\title{
Prospective evaluation of vitamin D levels in dental treated patients: A screening study
}

\author{
Maciej Krawiec ${ }^{\mathrm{A}-\mathrm{D}}$, Marzena Dominiak ${ }^{\mathrm{E}, \mathrm{F}}$ \\ Department of Oral Surgery, Wroclaw Medical University, Poland \\ A - research concept and design; $\mathrm{B}$ - collection and/or assembly of data; $\mathrm{C}$ - data analysis and interpretation; \\ $D$ - writing the article; $E$ - critical revision of the article; $F$ - final approval of the article
}

Address for correspondence
Maciej Krawiec

E-mail:maciej.krawiec@umed.wroc.pl

Funding sources

None declared

Conflict of interest

None declared

Received on September 24, 2020

Reviewed on March 16, 2021

Accepted on March 25, 2021

Published online on September 30, 2021

Cite as

Krawiec M, Dominiak M. Prospective evaluation of vitamin D levels in dental treated patients: A screening study. Dent Med Probl. 2021;58(3):321-326. doi:10.17219/dmp/134911

DOI

10.17219/dmp/134911

Copyright

๑ 2021 by Wroclaw Medical University

This is an article distributed under the terms of the

Creative Commons Attribution 3.0 Unported License (CC BY 3.0)

(https://creativecommons.org/licenses/by/3.0/).

\begin{abstract}
Background. The available epidemiological data indicates the existence of numerous tooth deficiencies and periodontopathies in the Polish population. Successful surgical treatment is dependent upon multiple factors, including bone quality, which is affected by vitamin D - one of the regulators of calcium (Ca) and phosphorus (P) metabolism.

Objectives. The aim of this study was to conduct a prospective evaluation of the levels of vitamin D among patients receiving dental treatment for various reasons (conservative, surgical or prosthodontic treatment).

Material and methods. The study involved 60 patients, who, for various reasons, were admitted for dental treatment for over a 1-week period in the summer season. A thorough interview together with a periodontological examination consisting of probing depth (PD) and clinical attachment level (CAL) measurements, were conducted. A total of $2 \mathrm{~mL}$ of blood was collected from each patient to determine the concentrations of vitamin D, parathyroid hormone (PTH), Ca, magnesium (Mg), and P in the blood with the use of mass spectrometry.

Results. Among the 60 patients enrolled in the study, 53 (88.3\%) showed vitamin D deficiency and 18 (30\%) showed a concentration below $17.8 \mathrm{ng} / \mathrm{mL}$, which is an independent general mortality factor. The difference in the level of vitamin $D$ between group $A$ (without periodontitis) and group $B$ (with periodontitis) was not statistically significant $(p=0.076)$, but a tendency for lower vitamin D levels in people with periodontitis was observed. We also observed a tendency for periodontal disease to occur more often with extreme vitamin D deficiency $(<15 \mathrm{ng} / \mathrm{mL})(p=0.730)$.

Conclusions. Low levels of vitamin D are present in a large proportion of dental patients, and an increase in the incidence of periodontal disease is likely associated with a decrease in the level of vitamin D.
\end{abstract}

Keywords: vitamin D, calcitriol, dental treatment, vitamin D deficit 


\section{Introduction}

Research to date has indicated that periodontopathies are socially debilitating ${ }^{1-6}$ and affect $\sim 90 \%$ of the adult Polish population. ${ }^{7-8}$ Indeed, an average Polish person over 35 has only 21 of their own teeth. This data shows the scale of periodontal disease in Poland, and indicates the need for periodontal and implant treatment in these patients.

Vitamin D occurs in 2 main forms: cholecalciferol (vitamin D3 of animal origin) and ergocalciferol (vitamin D2 of plant origin). This vitamin is a derivative of cholesterol and belongs to the family of secosteroid compounds. Vitamin D can be obtained from a proper diet; however, the vast majority $(\sim 90 \%)$ is synthesized in the human organism. The synthesis of the active form of vitamin D (calcitriol) is accomplished in several stages. The precursor, 7-dehydrocholesterol, can be found in the cell membranes of keratinocytes in the basal and spinous layers (collectively known as the Malpighian layer), and in the fibroblasts of the dermis. Upon exposure to ultraviolet (UV) radiation (290-315 nm), 7-dehydrocholesterol is converted into lumisterol and tachysterol. Then, under the influence of heat (skin temperature of $\sim 25^{\circ} \mathrm{C}$ ) and the reductase enzyme, these compounds are isomerized to cholecalciferol (calciol). Cholecalciferol is then released into the blood, where it binds to a specific vitamin D-binding globulin (protein DBP) and is transported to the liver. In the liver, hydroxylation occurs via 25-hydroxylase, leading to the formation of 25-hydroxy-cholecalciferol $(25(\mathrm{OH}) \mathrm{D}$; calcidiol). The biological activity of this compound is low and its excess is stored in adipocytes. The next stage takes place in the proximal tubules of the kidneys, where $1 \alpha$-hydroxylase (CYP27B1) converts calcidiol into 1,25-dihydroxycholecalciferol $(1,25(\mathrm{OH}) 2 \mathrm{D}$; calcitriol). Known as the vitamin hormone, the activity of calcitriol is 10,000 times higher than that of calcidiol, but its half-life is shorter, lasting 4-6 h. The $1 \alpha$-hydroxylation process also takes place in other cells and organs, such as macrophages, keratinocytes, the placenta, the parathyroid glands, prostate cells, osteoblasts, immune system cells, pancreatic islands, vascular smooth muscles, and cancer cells, where, through auto- and paracrine regulation, locally synthesized vitamin D affects local physiological processes. ${ }^{9-11}$

Chronic vitamin D deficiency results in abnormal calcium $(\mathrm{Ca})$ absorption in the small intestine, which can lead to a reduction in $\mathrm{Ca}$ blood concentration. Under these circumstances, the parathyroid glands increase the production of parathyroid hormone $(\mathrm{PTH})$, which, by affecting the bone, increases the release of $\mathrm{Ca}$ into the blood to compensate for the deficiency. This compensatory process is driven by the activation of osteoclasts, which can result in the destruction of bone tissue, leading, in turn, to a reduction in bone calcification, rickets, osteomalacia, and osteoporosis. The role of vitamin D in the bone mineralization process is further supported by the observation that bone tissue deteriorates during the winter/spring, when the synthesis of vitamin D through the action of sunlight is considerably reduced. Vitamin D can reduce bone resorption by increasing the intestinal absorption of $\mathrm{Ca}$ and its reabsorption in the distal renal tubules. However, it also accelerates the secretion of calcitonin and decreases the proliferation of parathyroid cells, which, in turn, inhibits the synthesis and activity of PTH. Vitamin D also aids bone repair processes and bone matrix synthesis, reduces the perforation of trabeculae, and increases the activity of bone growth factors.

\section{Objectives}

The aim of the paper was to conduct a prospective, observational screening study of the levels of vitamin D and $\mathrm{PTH}$ in patients undergoing dental treatment for various reasons.

\section{Material and methods}

This research was performed in full compliance with the Declaration of Helsinki and was approved by the local ethics committee (229/2019).

The study included patients who were, for various reasons, admitted to a private dental clinic for treatment for over a 1-week period during the summer season. The patients were thoroughly interviewed to obtain information concerning their general condition, and examined intraorally with a focus on history of chronic periodontal disease, tobacco smoking and the need for implant treatment. The patients were also informed about the importance of determining the level of vitamin $\mathrm{D}$ before each kind of dental treatment and its impact on general health. The study involved patients over 18 of both sexes. The exclusion criteria comprised active vitamin D supplementation, the use of UV lamps, pregnancy, and breastfeeding. Patients with general diseases that affect the level of vitamin $\mathrm{D}$, such as obesity, type 1 diabetes mellitus, inflammatory bowel disease, bronchial asthma, celiac disease, or hypertension, were also excluded from the study. All patients gave their voluntary and written consent to participate.

The incidence of periodontal disease was assessed in accordance with the classification of the American Academy of Periodontology for the Centers for Disease Control and Prevention (CDC); however, without the application of the disease severity classification. ${ }^{12}$ Probing depth (PD) from the margin of the gingiva to the bottom of the pocket was measured with a probe (in millimeters) on 4 surfaces of the following teeth: 16;11;26;36; 31; and 46 (right upper first molar; right upper medial incisor; left upper first molar; left lower first molar; left lower medial incisor; and right lower first molar). If the patient was lacking any of the examined teeth, the examination was not conducted at the site of the deficiency. If 2 or more sites with a periodontal pocket of at least $4 \mathrm{~mm}$ were ob- 
served, it was marked as periodontitis. The distance from the enamel-cement margin to the bottom of the pocket, measured with the use of a probe in millimeters on 4 surfaces of teeth $16,11,26,36,31$, and 46 , constituted the clinical attachment level (CAL).

A total of $2 \mathrm{~mL}$ of blood was collected from each patient's ulnar pit in order to determine the levels of vitamin D, PTH and electrolytes $(\mathrm{Ca}$, magnesium $(\mathrm{Mg})$ and phosphorus (P)). After collection, the samples were set aside for $20 \mathrm{~min}$ to coagulate at room temperature, and then were centrifuged at $3,000 \mathrm{rpm}$ for $10 \mathrm{~min}$. The serum was transferred to glass tubes marked with the code of the patient and subsequently frozen at $-20^{\circ} \mathrm{C}$. The samples were sent for analysis to the Laboratory of Quantitative Analysis of Drugs and Metabolites, which is part of the Laboratory of Mass Spectrometry in the Institute of Biochemistry and Biophysics at the Polish Academy of Sciences in Warsaw.

Vitamin D concentration in the blood serum was determined by means of liquid chromatography with tandem mass spectrometry (LC-MS/MS). This method is based on the technique of distinguishing single ions of the substances in the sample, using the measurements of the ion mass to ion charge ratio. Due to the stability of $25(\mathrm{OH})$ vitamin $\mathrm{D}$ in the blood serum, and the fact that the rate of its synthesis depends on the amount of vitamin D supplied with food, medications or supplements, it is believed to be the best indicator of vitamin $\mathrm{D}$ concentration in the organism. Laboratory methods measuring both the $25(\mathrm{OH}) \mathrm{D} 2$ and the $25(\mathrm{OH}) \mathrm{D} 3$ subunit, the sum of which constitutes the total concentration of vitamin $\mathrm{D}$ in the serum, were applied.

Statistical analysis was carried out using the IBM SPSS Statistics for Windows software, v. 25.0 (IBM Corp., Armonk, USA).

\section{Results}

Considering the results, it is worth noting that the level of vitamin D was measured in the summer, in August, which is associated with an increased vitamin D synthesis in the skin due to increased exposure to sunlight. Currently, a vitamin D level below $30 \mathrm{ng} / \mathrm{mL}$ is considered to be deficiency, while extreme deficiency is diagnosed when the value is below $15 \mathrm{ng} / \mathrm{mL}$. The reference ranges for $\mathrm{PTH}, \mathrm{Ca}, \mathrm{Mg}$, and P are $15.065 \mathrm{pg} / \mathrm{mL}, 8.8-10.2 \mathrm{mg} / \mathrm{dL}$, $1.58-2.55 \mathrm{mg} / \mathrm{dL}$, and $2.7-4.5 \mathrm{mg} / \mathrm{dL}$, respectively.

Sixty patients were enrolled in the study, including 42 women $(70 \%)$ and 18 men (30\%). The overall mean age of the patients was 46 years ( $\min 20$, $\max 85$ ), and the overall mean concentration of vitamin D was $23.2 \mathrm{ng} / \mathrm{mL}$. For women, the mean age was 44 and for men the mean age was 57 , and the mean levels of vitamin $\mathrm{D}$ for these groups were $24.28 \mathrm{ng} / \mathrm{mL}$ and $21.89 \mathrm{ng} / \mathrm{mL}$, respectively ( $p>0.05$; Mann-Whitney $U$ test).
A decreased level of vitamin D was observed in 53 individuals ( $88.3 \%$ of the group). These patients had a mean age of 47 years and an average vitamin D concentration of $21.7 \mathrm{ng} / \mathrm{mL}$, without any predilection with regard to sex. Among this group of patients, 37 were women (mean age 44) with a vitamin D concentration of $20.75 \mathrm{ng} / \mathrm{mL}$, while 16 were men (mean age 56) with a mean value of vitamin D concentration of $20.63 \mathrm{ng} / \mathrm{mL}$. Among patients with a normal concentration of vitamin $\mathrm{D}$, the average value was only $37 \mathrm{ng} / \mathrm{mL}$. In as many as 13 individuals, including 11 women and 2 men, extreme vitamin D deficiency $(<15 \mathrm{ng} / \mathrm{mL})$ was observed, with an average of $12 \mathrm{ng} / \mathrm{mL}$.

To examine the potential associations between periodontal disease and vitamin D levels, the patients were divided into 2 groups. The $1^{\text {st }}$ group (A) consisted of 28 patients without periodontal disease and the $2^{\text {nd }}$ group (B) comprised 32 patients with periodontal disease $(53.3 \%$ of all patients; mean age 55 ). The mean vitamin D levels were $24.8 \mathrm{ng} / \mathrm{mL}$ in group A and $21.7 \mathrm{ng} / \mathrm{mL}$ in group B. There was no statistically significant difference between these groups ( $p=0.076$; Mann-Whitney $U$ test). In 30 persons from group $B$, the level of vitamin $D$ was decreased (mean $(M): 19.2 \mathrm{ng} / \mathrm{mL}$; mean age 56 ).

It is noticeable that the incidence of periodontal disease increases with a decrease in the level of vitamin D. Three people out of 7 (42.9\%) had periodontal disease in the group where the concentration was normal. In the group with vitamin D levels at the range of $15-30 \mathrm{ng} / \mathrm{mL}$, 21 people out of 40 (52.5\%) showed periodontal disease, and in the group with vitamin D levels $<15 \mathrm{ng} / \mathrm{mL}$, it was 8 people out of 13 (61.5\%) (Fig. 1). We could also observe a tendency for periodontal disease to occur more often in patients with extreme vitamin D deficiency $(<15 \mathrm{ng} / \mathrm{mL})$ as compared to those with a normal vitamin D concentration (>30 ng/mL) ( $p=0.730 ; \chi^{2}$ test).

It was noticed that the level of vitamin $\mathrm{D}$ decreased with age. The mean age when the level of vitamin $\mathrm{D}$ was $<15 \mathrm{ng} / \mathrm{mL}$ was 51 , and for $>30 \mathrm{ng} / \mathrm{mL}$, it was 47 . However, this difference was not statistically significant $(p>0.05$; Mann-Whitney $U$ test).

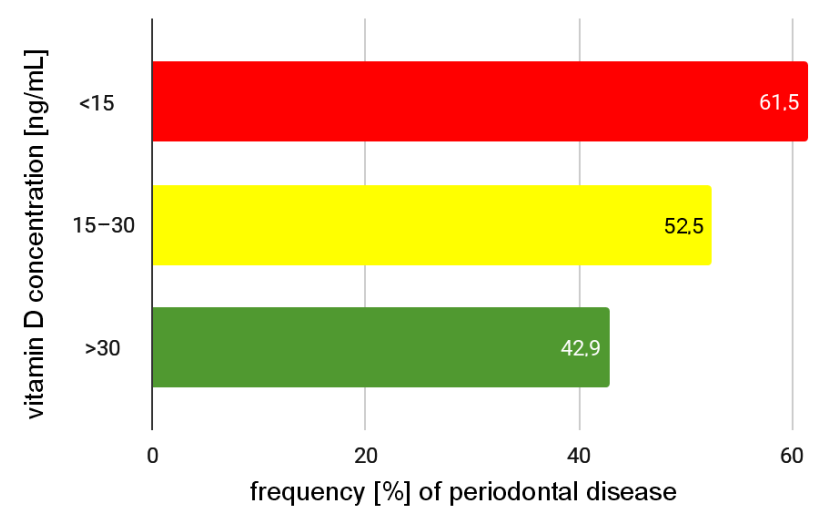

Fig. 1. Distribution of the incidence of periodontal disease in relation to vitamin D concentration

Data presented as means (M). 
The average concentration of vitamin $\mathrm{D}$ in women above 50 was $22.15 \mathrm{ng} / \mathrm{mL}$, which can be associated with an increased risk of osteoporosis and a decrease in estrogen concentration. ${ }^{13}$

It was also observed that the concentration of PTH increased with a decrease in the level if vitamin $\mathrm{D}$ (>30 ng/mL, 15-30 ng/mL, <15 ng/mL), but there were no statistically significant differences between these groups ( $p>0.05$; Mann-Whitney $U$ test). In individuals with a normal concentration of vitamin $\mathrm{D}$, the mean level of PTH was $34.56 \mathrm{pg} / \mathrm{mL}$, in those with a concentration of vitamin $\mathrm{D}<30 \mathrm{ng} / \mathrm{mL}$, the mean level of PTH was $43.84 \mathrm{pg} / \mathrm{mL}$, and in the case of extreme vitamin $\mathrm{D}$ deficiency, the mean level of PTH was $47.54 \mathrm{pg} / \mathrm{mL}$. Overall, the average level of PTH was $44.37 \mathrm{pg} / \mathrm{mL}$. In group $\mathrm{B}$ (with periodontal diseases), the mean level of PTH was $48.65 \mathrm{pg} / \mathrm{mL}$, and in group A (without periodontal diseases), the mean level was $38.75 \mathrm{pg} / \mathrm{mL}$.

The concentrations of electrolytes ( $\mathrm{Ca}, \mathrm{Mg}$ and $\mathrm{P}$ ) were within the normal range for all participants. When the concentration of vitamin $\mathrm{D}$ was $15-30 \mathrm{ng} / \mathrm{mL}$, the concentration of $\mathrm{Ca}$ amounted to $9.40 \mathrm{mg} / \mathrm{dL}$, the concentration of $\mathrm{Mg}$ was at $1.86 \mathrm{mg} / \mathrm{dL}$ and the concentration of $\mathrm{P}$ was $3.57 \mathrm{mg} / \mathrm{dL}$. When the level of vitamin $\mathrm{D}$ was $<15 \mathrm{ng} / \mathrm{mL}$, the values for these electrolytes were equal to $8.81 \mathrm{mg} / \mathrm{dL}, 1.83 \mathrm{mg} / \mathrm{dL}$ and $3.31 \mathrm{mg} / \mathrm{dL}$, respectively (Fig. 2). The overall average levels for these electrolytes were as follows: $\mathrm{Ca}-9.47 \mathrm{mg} / \mathrm{dL} ; \mathrm{Mg}-2.02 \mathrm{mg} / \mathrm{dL}$; and $\mathrm{P}-3.42 \mathrm{mg} / \mathrm{dL}$. In group $\mathrm{B}$ (with periodontal disease), they were: $\mathrm{Ca}-9.52 \mathrm{mg} / \mathrm{dL} ; \mathrm{Mg}-1.98 \mathrm{mg} / \mathrm{dL}$; and $\mathrm{P}-3.32 \mathrm{mg} / \mathrm{dL}$, and in group A (without periodontal disease), they were: $\mathrm{Ca}-9.43 \mathrm{mg} / \mathrm{dL} ; \mathrm{Mg}-2.03 \mathrm{mg} / \mathrm{dL}$; and $\mathrm{P}-3.52 \mathrm{mg} / \mathrm{dL}$.

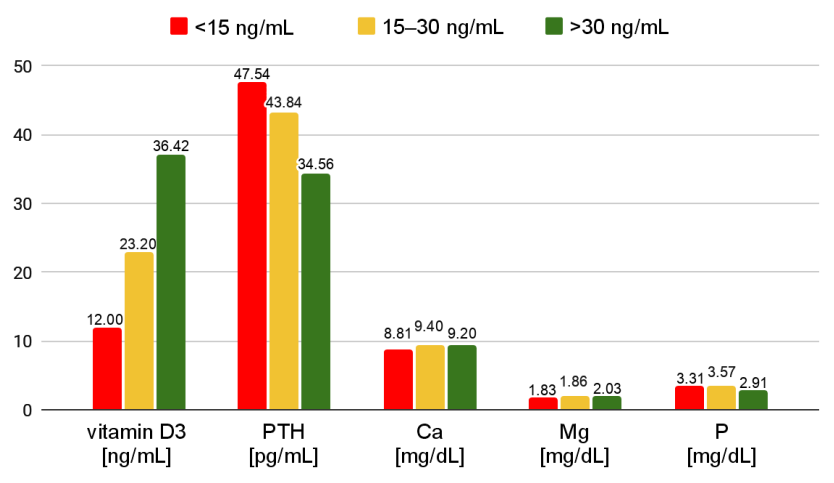

Fig. 2. Distribution of parameters depending on the study group

PTH - parathyroid hormone; Ca - calcium; Mg - magnesium; P - phosphorus; bars refer to groups with various levels of vitamin $D$.

Data presented as means (M).

It should be emphasized that a vitamin $\mathrm{D}$ concentration below $17.8 \mathrm{ng} / \mathrm{mL}$ is considered to be an independent general mortality factor. ${ }^{14}$ In our study, such concentration or lower was observed in 18 patients, which constitutes $30 \%$ of all patients.

\section{Discussion}

Vitamin D plays an important role in the stomatognathic system, where its impact on caries prevention has been shown. ${ }^{15}$ This vitamin can also modulate Behçet's disease, aphthosis and Sjögren's syndrome. ${ }^{16}$ Vitamin D3 hypovitaminosis is a risk factor for the occurrence of pathological periodontal pockets and gingivitis, and the loss of bone mass; it can also decrease the efficacy of the organism's defense systems. ${ }^{17}$ This vitamin is capable of modifying the course of periodontal disease through 3 basic mechanisms: the maintenance of normal bone metabolism; antibacterial activity; and anti-inflammatory activity. ${ }^{18}$ The antibacterial activity of vitamin $\mathrm{D}$ is mainly based on the induction of the secretion of beta-defensins and cathelicidin LL-37. The anti-inflammatory activity is realized through the inhibition of the release of cytokines interleukin (IL)-1 $\beta$, IL-6 and IL-12, a decrease in the number of T and B cells, and blocking the pro-inflammatory activity of Th1 and Th17 cells. This activity of vitamin D was confirmed in a study conducted by Oteri et al., where it was demonstrated that an increase in the level of vitamin D reduced the inflammatory response and resulted in improved healing after the surgical extraction of third molar. ${ }^{19}$

In light of the abovementioned reports, scientists began to examine the possible correlations between the activity of vitamin D and the course of periodontal disease more carefully. There are reports that link vitamin D to a decreased loss of the alveolar process bone and a decreased loss of connective tissue attachment, while others have shown positive effects of vitamin D activity and Ca supplementation in terms of improved bone density. ${ }^{20-22}$ Bashutski et al. assessed the effects of vitamin D on wound healing and periodontal treatment results. ${ }^{23}$ In patients with initial vitamin D deficiency, an increase in CAL was much smaller and PD was much greater than in individuals where the level of vitamin $\mathrm{D}$ was normal. ${ }^{23}$ Leszczyszyn also observed that periodontal disease occurred much more frequently in patients who did not supplement vitamin D (59.3\% vs $39.3 \%$, respectively). ${ }^{24}$ The percentage of patients with a low value of CAL $(60.5 \%$ vs $32.0 \% ; p=0.010)$, recessions $(59.3 \%$ vs $35.7 \%$; $p=0.030)$, pathological alveolar pockets $(33.7 \%$ vs $10.7 \% ; p=0.028)$, and periodontal disease $(60.5 \%$ vs $35.7 \% ; p=0.039)$ was greater in the group of individuals with vitamin D deficiency as compared to the group of individuals where the concentration of vitamin D was optimal. ${ }^{24}$

Studies examining the impact of vitamin D on implant treatment and bone augmentation procedures also can be found in the literature. Schulze-Späte et al. investigated whether oral supplementation with vitamin D3 (5,000 IU) in combination with $\mathrm{Ca}(600 \mathrm{mg})$ would affect bone formation and reconstruction after maxillary sinus augmentation; however, no statistically significant difference was observed in this study. ${ }^{25}$ In some clinical situations, an alternative to regenerative procedures is the use of short dental implants. Studies have shown that, in many clinical situations, short 
implants are a good alternative to the regular length of implants, despite the often unfavorable ratio of the crown length to the implant length. ${ }^{26,27}$ Studies on the impact of vitamin D deficiency on implant loss due to incorrect osseointegration have been carried out. A tendency (without statistical significance) for an increased risk of implant loss with an increase in vitamin D deficiency was demonstrated. ${ }^{28-30}$

Given the above findings, it has become clear that it is necessary to increase the level of vitamin D through proper supplementation. ${ }^{31}$ The reasons for the observed deficiency may include the impairment of supply and intestinal absorption, sunlight deficiency, disturbed renal and/or hepatic metabolism, or disorders associated with vitamin D receptor (VDR) abnormalities. ${ }^{32}$ It is also extremely important to take vitamin $\mathrm{K} 2 \mathrm{MK} 7$, as one of its functions includes the activation and enhancement of GLA proteins, including osteocalcin and matrix GLA protein (MGP), which can affect bone quality. Vitamin D should be supplemented in drops, taken after meals for better absorption. ${ }^{33}$ The recommended total dose of vitamin D during the treatment can be calculated on the basis of Gronningen's formula (Equation 1):

$$
40 \times\left(75-\begin{array}{c}
\text { concentration } \\
\text { of } 25(\mathrm{OH}) \mathrm{D}
\end{array}[\mathrm{nmol} / \mathrm{l}]\right) \times \underset{\operatorname{mass}}{\operatorname{body}}[\mathrm{kg}]
$$

where:

$1 \mathrm{ng} / \mathrm{mL}=2.5 \mathrm{nmol} / \mathrm{mL}^{34}$

Vitamin D can be supplied with the administration of ergocalciferol (vitamin D2), cholecalciferol (vitamin D3) or calcifediol $(25(\mathrm{OH}) \mathrm{D} 3)$. The latter is used in the treatment of liver diseases, and for complications associated with glucocorticosteroid treatment or treatment with antiepileptic drugs. The administration of calcitriol and its derivatives has no impact on the improvement of vitamin D3 parameters, defined as an increase in $25(\mathrm{OH}) \mathrm{D} 3$ concentration in the blood serum. The authors recommend the supplementation of vitamin D3 depending on the general condition and the level of deficiency as outlined in Table 1.

A limitation of our study may be the fact that it was conducted in the summer period, when the synthesis of vitamin D in the body is higher. This may have had an impact on obtaining a trend rather than a statistically significant result regarding the level of vitamin $\mathrm{D}$ and the frequency of periodontal disease. Another element that could have affected the results was the collection of blood from the ulnar vein and not from the capillaries.

Table 1. Recommended vitamin D supplementation depending on the level of deficiency

\begin{tabular}{|c|c|}
\hline $\begin{array}{c}\text { Vitamin D level } \\
{[\mathrm{ng} / \mathrm{mL}]}\end{array}$ & $\begin{array}{c}\text { Supplementation } \\
>30 \text { (normal level) }\end{array}$ \\
$20-30$ & 4,000 IU per day throughout the year \\
$<20$ & $8,000 \mathrm{IU}$ per day, follow-up after 3 months \\
\hline$<$ & 10,000 IU per day, follow-up after 3 months \\
\hline
\end{tabular}

\section{Conclusions}

The analysis of the current results has shown that decreased levels of vitamin D are present in a large proportion of dental patients, and that an increase in the incidence of periodontal disease is likely associated with a decrease in the level of vitamin D. The level of vitamin D tends to decrease with age and in persons with periodontal disease. Thus, vitamin $\mathrm{D}$ concentration should be determined before periodontal procedures and, if needed, supplementation should be administered.

\section{ORCID iDs}

Maciej Krawiec (1) https://orcid.org/0000-0002-2871-7682

Marzena Dominiak (1) https://orcid.org/0000-0001-8943-0549

\section{References}

1. Adams JS, Hewison M. Update in vitamin D. J Clin Endocrinol Metab. 2010;95(2):471-478. doi:10.1210/jc.2009-1773

2. Płudowski P, Karczmarewicz E, Chlebna-Sokół D, et al. Vitamin D supplementation in healthy population and risk groups of vitamin D deficiency - practice guidelines for Central Europe 2013 [in Polish]. Stand Med Pediatr. 2013;10:573-578.

3. Karczmarewicz E, Czekuc- Kryskiewicz E, Płudowski P. Effect of vitamin D status on pharmacological treatment efficiency: Impact on cost-effective management in medicine. Dermatoendocrinol. 2013;5(2):299-304. doi:10.4161/derm.25279

4. Holick MF. Ressurection of vitamin D deficiency and rickets. J Clin Invest. 2006;116(8):2062-2072. doi:10.1172/JCI29449

5. Cashman KD, Dowling KG, Škrabáková Z, et al. Vitamin D deficiency in Europe: Pandemic? Am J Clin Nutr. 2016;103(4):1033-1044. doi:10.3945/ajen.115.120873

6. Grant WB, Fakhoury HMA, Karras SN, Al Anouti F, Bhattoa HP. Variations in 25-hydroxyvitamin $D$ in countries from the Middle East and Europe: The roles of UVB exposure and diet. Nutrients. 2019;11(9):2065. doi:10.3390/nu11092065

7. Konopka T, Dembowska E, Pietruska M, Dymalski P, Górska R. Periodontal status and selected parameters of oral condition of Poles aged 65 to 74 years [in Polish]. Przegl Epidemiol. 2015;69(3):643-647.

8. Górska R, Pietruska M, Dembowska E, Wysokińska-Miszczuk J, Włosowicz M, Konopka T. Prevalence of periodontal diseases in 35-44 year-olds in the large urban agglomerations [in Polish]. Dent Med Probl. 2012;49(1):19-27.

9. Alpert PT, Shaikh U. The effects of vitamin D deficiency and insufficiency on the endocrine and paracrine systems. Biol Res Nurs. 2007;9(2):117-129. doi:10.1177/1099800407308057

10. DeLuca HF. Overview of general physiologic features and functions of vitamin D. Am J Clin Nutr. 2004;80(6 Suppl):1689S-1696S. doi:10.1093/ajcn/80.6.1689S

11. Krawiec $M$, Dominiak $M$. The role of vitamin $D$ in the human body with a special emphasis on dental issues: Literature review. Dent Med Probl. 2018;55(4):419-424. doi:10.17219/dmp/99051

12. Page RC, Eke PI. Case definitions for use in population-based surveillance of periodontitis. J Periodontol. 2007;78(7 Suppl):1387-1399. doi:10.1902/jop.2007.060264

13. Richy F, Schacht E, Bruyere O, Ethgen O, Gourlay M, Reginster JY. Vitamin $D$ analogs versus native vitamin $D$ in preventing bone loss and osteoporosis-related fractures: A comparative meta-analysis. Calcif Tissue Int. 2005;76(3):176-186. doi:10.1007/s00223-004-0005-4

14. Drechsler D, Pilz S, Obermayer-Pietsch B, et al. Vitamin D deficiency is associated with sudden cardiac death, combined cardiovascular events, and mortality in haemodialysis patients. Eur Heart J. 2010;31(18):2253-2261. doi:10.1093/eurheartj/ehq246

15. Kosińska J, Billing-Marczak K, Krotkiewski M. New unknown functions of vitamin D [in Polish]. Med Rodz. 2008;2:34-47.

16. Glerup H, Mikkelsen K, Poulsen L, et al. Hypovitaminosis D myopathy without biochemical signs of osteomalacic bone involvement. Calcif Tissue Int. 2000;66(6):419-424. doi:10.1007/s002230010085 
17. Grant WB, Boucher BJ. Are Hill's criteria for causality satisfied for vitamin D and periodontal disease? Dermatoendocrinol. 2010;2(1):30-36. doi:10.4161/derm.2.1.12488

18. McMahon L, Schwartz K, Yilmaz O, Brown E, Ryan LK, Diamond G. Vitamin D-mediated induction of innate immunity in gingival epithelial cells. Infect Immun. 2011;79(6):2250-2256. doi:10.1128/IAI.00099-11

19. Oteri $G$, Cicciù $M$, Peditto $M$, et al. Does vitamin $D 3$ have an impact on clinical and biochemical parameters related to third molar surgery. J Craniofac Surg. 2016;27(2):469-476. doi:10.1097/ SCS.0000000000002389

20. Stein SH, Livada R, Tipton DA. Re-evaluating the role of vitamin D in the periodontium. J Periodontal Res. 2014;49(5):545-553. doi:10.1111/jre.12149

21. Perayil J, Menon KS, Kurup S, et al. Influence of vitamin D \& calcium supplementation in the management of periodontitis. J Clin Diagn Res. 2015;9(6):ZC35-ZC38. doi:10.7860/JCDR/2015/12292.6091

22. Laky M, Bertl K, Haririan $\mathrm{H}$, et al. Serum levels of 25 -hydroxyvitamin D are associated with periodontal disease. Clin Oral Investig. 2017;21(5):1553-1558. doi:10.1007/s00784-016-1965-2

23. Bashutski JD, Eber RM, Kinney JS, et al. The impact of vitamin D status on periodontal surgery outcomes. J Dent Res. 2011;90(8):1007-1012. doi:10.1177/0022034511407771

24. Leszczyszyn A. Prospective evaluation of the effect of vitamin D3 concentration on the muco-osseous-gingival system in patients with malocclusion (PhD thesis). Wroclaw Medical University, Poland. 2019. https://bip.umed.wroc.pl/artykul/184/2039/anna-leszczyszynprzewod-doktorski. Accessed September 1, 2020.

25. Schulze-Späte U, Dietrich T, Wu C, Wang K, Hasturk H, Dibart S Systemic vitamin D supplementation and local bone formation after maxillary sinus augmentation - a randomized, double-blind, placebo-controlled clinical investigation. Clin Oral Implants Res. 2016;27(6):701-706. doi:10.1111/clr.12641

26. Hadzik J, Krawiec M, Kubasiewicz-Ross P, Prylińska-Czyżewska A, Gedrange T, Dominiak M. Short implants and conventional implants in the residual maxillary alveolar ridge: A 36-month follow-up observation. Med Sci Monit. 2018;24:5645-5652. doi:10.12659/MSM.910404

27. Hadzik J, Krawiec M, Sławecki K, Kunert-Keil C, Dominiak M, Gedrange T. The influence of the crown-implant ratio on the crestal bone level and implant secondary stability: 36 -month clinical study. BioMed Res Int. 2018;4246874. doi:10.1155/2018/4246874

28. Javed F, Malmstrom H, Kellesarian SV, Al-Kheraif AA, Vohra F, Romanos GE. Efficacy of vitamin D3 supplementation on osseointegration of implants. Implant Dent. 2016;25(2):281-287. doi:10.1097/ID.0000000000000390

29. Fretwurst T, Grunert S, Woelber JP, Nelson K, Semper-Hogg W. Vitamin D deficiency in early implant failure: Two case reports. Int J Implant Dent. 2016;2:24. doi:10.1186/s40729-016-0056-0

30. Mangano F, Mortellaro C, Mangano N, Mangano C. Is low serum vitamin $\mathrm{D}$ associated with early dental implant failure? A retrospective evaluation on 1625 implants placed in 822 patients. Mediators Inflamm. 2016;2016:5319718. doi:10.1155/2016/5319718

31. Burt LA, Billington EO, Rose MS, Raymond DA, Hanley DA, Boyd SK. Effect of high-dose vitamin $D$ supplementation on volumetric bone density and bone strength: A randomized clinical trial. JAMA. 2019:322(8):736-745. doi:10.1001/jama.2019.11889

32. Blann A. An update on vitamin D deficiency and at risk groups. J Fam Health. 2015;25(3):16-19.

33. Khayyatzadeh SS, Bagherniya M, Abdollahi Z, Ferns GA, GhayourMobarhan $M$. What is the best solution to manage vitamin $D$ deficiency? IUBMB Life. 2019;71(9):1190-1191. doi:10.1002/iub.2038

34. van Groningen $L$, Opdenoordt $S$, van Sorge $A$, Telting $D$, Giesen A, de Boer H. Cholecalciferol loading dose guideline for vitamin D-deficient adults. Eur J Endocrinol. 2010;162(4):805-811. doi:10.1530/EJE-09-0932 